\title{
The effects of postweaning rearing conditions on the response to stressful tasks in the rat
}

\author{
AIDAN ALTENOR \\ University of Pennsylvania, Philadelphia, Pennsylvania 19104 \\ and \\ EDWIN J. KAY \\ Lehigh University, Bethlehem, Pennsylvania 18015
}

\begin{abstract}
The effects of individual- and group-housing conditions were examined in three experiments. In Experiment 1, individually housed rats were more susceptible to sudden death by drowning than were group-housed rats, and daily handling increased this susceptibility. In Experiment 2, the test was one typically used in "learned helplessness" experiments, escape from shock. Individually housed animals took longer to escape from shock than did animals housed in groups. In Experiment 3, individually housed and group-housed rats were handled and given either no further treatment or electroconvulsive shock (ECS) or a change in housing conditions before being tested for escape from shock. Animals individually housed throughout were slower to escape shock than were each of the other five groups. These findings suggest that there are both behavioral and physiological similarities between the operations of individual housing and exposure to inescapable shock. Explanations in terms of learned helplessness and noradrenergic depletion are discussed.
\end{abstract}

Richter (1957) reported that wild rats subjected to a stressful swimming task die within minutes, while laboratory rats survive as long as $60 \mathrm{~h}$. The psychological factor of "hopelessness" was used to account for this "sudden death" phenomenon, especially since the rats survive longer if repeatedly placed in and removed from the stressful swimming situation before being tested. According to Richter (1957), the rats develop a "sense of hope" which mediates the persistent behavior during the test.

Although Richter (1957) linked the sudden death phenomenon to the wildness of the rats, Lynch and Katcher (1974) reported that rats which receive human handling from weaning to adulthood die more often in the Richter chamber than do unhandled rats. Similarly, Rosellini, Binik, and Seligman (1976) showed that human handling potentiates susceptibility to sudden death in animals that are individually housed.

Experiments 1 and 2 constituted parts of a dissertation submitted to Lehigh University in partial fulfillment of the requirements for the PhD degree by the principle investigator, who was supported by a fellowship from the National Fellowships Fund. Experiment 3 was supported by a grant to and conducted in the laboratory of Martin E. P. Seligman (NH 19604) and by an NIMH postdoctoral fellowship (MH 07682) to the principle investigator. We thank Randall P. Grant and Paul Stelmach for their assistance in conducting the Experiment 3, and M. E. P. Seligman, J. R. Volpicelli, E. F. Gottheil for their comments on an earlier draft of this manuscript. Direct requests for reprints to Edwin J. Kay, Department of Psychology, Chandler-Ullman Hall, No. 17, Lehigh University, Bethlehem, Pennsylvania 18015.
The psychological explanations used to account for the sudden death phenomenon-" "hopelessness" (Richter, 1957) and "learned helplessness" (Seligman, 1975) - have been called into question by Hughes and Lynch (1978), who assert that it may be difficult to empirically verify the existence of such psychological states in infrahuman animals and that it may be more parsimonious to seek behavioral and physiological hypotheses to account for the phenomenon. Here we report experiments that examine behavioral and physiological similarities between the effects of individual housing and of inescapable shock.

\section{EXPERIMENT 1}

In Lynch and Katcher's (1974) experiment, susceptibility to sudden death was unaffected by the difference between individual and paired housing. Handling was the crucial variable. Rosellini et al. (1976) found in one experiment that both individual housing (as compared to group housing, with four or five animals in a group) and human handling led to more sudden deaths in the swimming situation, with human handling potentiating the rat's susceptibility to sudden death; they found, in a second experiment, that individual housing had a detrimental effect but with no increase in susceptibility to sudden death in the handled animals. In Rosellini et al.'s experiments, group housing clearly served a protective function. The role of human handling was less clear. 
The above findings present a confusing account of the effects of housing and handling on the rat's ability to survive a stressful swim. The two studies, although using the same strain, differed in the number of rats in the group condition and in the size of the living compartments. Lynch and Katcher had two animals in their group-housing conditions, while Rosellini et al. had four and five animals per group. In Experiment 1 , we sought to reproduce the effects of individual housing using Rosellini et al.'s procedure.

\section{Method}

Subjects. The subjects were 64 male Sprague-Dawley rats, obtained from the Holtzman Company (Madison, Wisconsin) at 24 days of age and maintained on a 12-h light/dark cycle. All experimental manipulations were conducted during the light phase of the cycle. Food and water were available ad lib in all housing conditions. Room temperature was maintained at $24^{\circ} \pm 3^{\circ} \mathrm{C}$.

Apparatus. Individual housing was in $20.3 \times 25.4 \times 17.8 \mathrm{~cm}$ cages, group housing (four animals to a group) in $40.6 \times 53.3 \times$ $45.2 \mathrm{~cm}$ cages. The animals were tested in a cylindrical acrylic plastic tank, $76 \mathrm{~cm}$, high and $20.3 \mathrm{~cm}$ in diameter. A $.64-\mathrm{cm}$ jet of $35^{\circ} \mathrm{C}$ water was directed into the center of the tank at a pressure of $.42 \mathrm{~kg} / \mathrm{cm}^{2}$. The water level in the tank was maintained at a height of $64 \mathrm{~cm}$.

Procedure. Upon arrival from the Holtzman Company, 16 subjects were randomly assigned to each of four treatment conditions: individually housed and handled ( $\mathrm{IH})$, individually housed and not handled (IN), group-housed and handled (GH), and group-housed and not handled(GN). Handled animals were handled by the same experimenter for approximately $15 \mathrm{sec}$ per day every day between the ages of 25 and 100 days: the animal was removed from its home cage, placed on the experimenter's left arm, and stroked from head to tail seven to nine times. The animals were then picked up (two or three times) around the back with the experimenter's thumb and index finger around the front paws and placed back on the experimenter's arm. At 100 days of age, the animals were tested in the swim tank. A test session consisted of a maximum of $30 \mathrm{~min}$ of swimming. The time of death, if it occurred, was recorded.'

\section{Results and Discussion.}

Death, when it occurred in the tank, was rapid (mean $=7.5 \mathrm{~min}$; range $=2-22 \mathrm{~min}$ ). The $\mathrm{IH}$ group showed the highest percentage of death $(69 \%)$, the IN group the next highest (31\%), and the GH and GN groups, the lowest $(6 \%$ and $12 \%$, respectively). A chi-square analysis was applied to the data in this 2 by 2 design. Individual-housing conditions resulted in more deaths than did group-housing conditions $\left[\chi^{2}(1)=12.65, \mathrm{p}<.001\right]$. Handling had no effect $\left[\chi^{2}(1)=1.87\right]$; however, the interaction of handling with housing was marginally significant $\left[\chi^{2}(1)=3.67\right.$, $\mathrm{p}=.055]$. Only for the individually housed animals did handling lead to more deaths. This may reflect a "floor" effect.

These findings replicate in detail those obtained by Rosellini et al. (1976), and suggest that individual housing is the crucial factor responsible for death in the stressful swimming situation. These findings are discordant with those reported by Lynch and Katcher (1974), who found no difference between individually and group-housed animals. One possible reason for this discrepancy is that the group-housing condition of Lynch and Katcher, in having only two animals per group, may not have differed sufficiently from the individual-housing condition to produce any effect.

While Rosellini et al. (1976) explained their findings in terms of the psychological state of "helplessness" induced by the individual rearing condition, neither their experiments nor our Experiment 1 provides any direct evidence that the operations used produce a "helpless" animal. The operations that induce "helplessness" (cf. Maier \& Seligman, 1976) are similar to the operations used in Experiment 1 in that both are stressors. Individual housing, which is presumed to produce "isolation stress," has been found to produce behavioral and emotional deficits in a variety of species (e.g., Ader, 1967; Kaufman, 1973; Lessac \& Solomon, 1969; Scott, Stewart, \& DeGhett, 1973; Seligman \& Groves, 1970). Similarly, exposure to inescapable shock produces behavioral deficits in a variety of species (cf. Maier \& Seligman, 1976, for a recent review). Whatever status "learned helplessness" has as a theory, it remains a label for a set of empirical observations. Accordingly, Experiment 2 was designed to assess the effects of the operations of Experiment 1 on the shockescape task that Maier, Albin, and Testa (1973) used to assess "helplessness" following pretreatment with inescapable shock.

\section{EXPERIMENT 2}

\section{Method}

Subjects. The subjects were 48 male Sprague-Dawley rats, as used in Experiment 1.

Apparatus. Shock-escape performance was tested in a two-way shuttlebox, $60.86 \times 19.05 \times 22.60 \mathrm{~cm}$, constructed of $.64-\mathrm{cm}$ clear acrylic plastic. The center of the shuttlebox contained a clear acrylic plastic divider with a rounded archway, $7.8 \mathrm{~cm}$ high and $6.0 \mathrm{~cm}$ wide. The grid floor consisted of .32-cm stainless steel bars, $1.6 \mathrm{~cm}$ apart. The floor of each chamber was hinged at the center of the cage and suspended from springs at the end so that the downward deflection of the floor caused by the entry of the animal produced a switch closure. A Grason-Stadler shock generator (Model E6070B) supplied a 1.0-mA scrambled shock to the floor of the unit. Response latencies were automatically recorded by an electric timer to the nearest $.01 \mathrm{sec}$. Automatic relay and timing devices monitored the operation during shock-escape testing.

Procedure. Twelve subjects were assigned randomly to each of four treatment conditions: IH, IN, GH, and GN. Handled animals were treated as in Experiment 1. At 100 days of age, all subjects received 30 shock-escape trials in the shuttlebox.

First, each animal was allowed $5 \mathrm{~min}$ to habituate to the apparatus. The escape procedure (after Maier et al., 1973) consisted of five FR-1 shock-escape trials, during which the animal was required to shuttle once in order to terminate the shock, followed by 25 FR-2 shock-escape trials, during which the animal was required to enter one compartment, then reenter the original compartment in order to terminate the shock. Shock termination occurred $20 \mathrm{sec}$ after the initiation of a trial if the animal failed to execute the appropriate escape response. There was no avoidance contingency. The intertrial interval was $60 \mathrm{sec}$. During all phases of testing, a BRS/Foringer noise generator (Model AU 902) supplied $85 \mathrm{~dB}$ of white noise to the experimental chamber.

\section{Results and Discussion.}

The mean latency to respond was computed for each rat for both the FR-1 and FR-2 trials. Separate 2 by 2 
analyses of variance were conducted on the FR-1 and FR-2 data.

Analysis of the FR-1 data revealed no statistically reliable effects. This finding is consistent with those reported by Maier et al. (1973).

The mean latencies to escape for the FR-2 data were $11.2 \mathrm{sec}$ for the IH group, $8.1 \mathrm{sec}$ for the IN group, $6.0 \mathrm{sec}$ for the GH group, and $5.7 \mathrm{sec}$ for the GN group. A 2 (individual and group housing) by 2 (handling and not handling) analysis of variance revealed that individually housed animals took longer to escape from shock than group-housed animals $[F(1,44)=14.31, p<.001]$. Neither the effect of handling $[F(1,44)=3.08]$ nor the interaction $[F(1,44)=2.10]$ reached significance.

The results show that individual housing produces a deficit in responding in the FR-2 shock-escape task. If we can attribute this failure to the animal's being "helpless," then we can conclude that individual housing produces a helpless animal, and that this, in turn, leads to more frequent sudden death in the swimming apparatus.

Seligman and his associates (cf. Maier \& Seligman, 1976) have proposed that the deficit produced by inescapable shock results from the animal's learning that it cannot do anything to control the termination of the aversive event. This statement derives from the use of a triadic design in which one animal receives escapable shock, a yoked partner receives the same amount of shock but its escape partner determines the duration, and a naive, nonpreshocked animal. Subsequent to escapable, inescapable, or no shock, all animals are tested in a new situation. The typical finding (e.g., Glazer \& Weiss, 1976; Maier et al., 1973) is that animals that received escapable shock do not differ from the nonpreshocked group but the inescapably shocked group shows a marked retardation in learning relative to the other two groups.

Although Seligman has couched his explanation in terms of a psychological construct, alternative hypotheses have been proposed which account for the effects of inescapable shock in terms of its psychological effects (Anisman, 1975; Weiss, Glazer, \& Pohorecky, 1976). Weiss $(1968,1971 \mathrm{a}, 1971 \mathrm{~b}, 1971 \mathrm{c})$ has shown that inescapable shock produces more disruption of physiological processes (e.g., ulceration, weight loss) than escapable shock. He has also reported that inescapable shock results in depletion of norepinephrine, and has proposed that the behavioral deficits produced by inescapable shock are mediated by this norepinephrine depletion (Weiss et al., 1976; Weiss, Stone, \& Harrell, 1970). Furthermore, Dorworth and Overmier (1977), Lambert, Harrell, and EmmetOglesby (Note 1), and Pavlik (Note 2), have reported that the administration of electroconvulsive shock (ECS) ameliorates the disruptive effects of inescapable shock. ECS has been demonstrated to result in increases in brain norepinephrine levels (e.g., Hinesly, Norton, \& Aprison, 1968; Kety, Javoy, Thierry, \& Glowinski, 1967). Isolated rearing conditions have also been reported to result in a reduction in the rates of biosynthesis and utilization of norepinephrine in the brain of rodents, and group housing reverses this process (Welch \& Welch, 1971). If the debilitative effects of prolonged individual housing are, in part, mediated by changes in brain norepinephrine levels, then treatments which have the opposite effects on brain norepinephrine levels should ameliorate the debilitative effects. Thus, we chose to examine the "therapeutic" effects of ECS administration and group housing. We were also interested in the protective effects of group housing: Would group-housed animals learn less after a period of individual housing?

\section{EXPERIMENT 3}

\section{Method}

Subjects. The subjects were 48 male Sprague-Dawley rats as in Experiment 1.

Apparatus. Individual housing occurred in $20.3 \times 25.4 \times 17.8 \mathrm{~cm}$ cages, group housing (four animals to a group) in $43.2 \times 24.1 \times$ $17.8 \mathrm{~cm}$ cages. Shock-escape testing was conducted in a shuttlebox, $47.0 \mathrm{~cm}$ long, $20.4 \mathrm{~cm}$ wide, and $19.7 \mathrm{~cm}$ high. The walls were constructed of stainless steel, and the ceiling of clear acrylic plastic. The floor consisted of a stainless steel grid with .4-cm-diam bars, $1.9 \mathrm{~cm}$ apart. The chamber was divided into two identical sections by a metal divider with a rounded archway, $7.8 \mathrm{~cm}$ high and $5.8 \mathrm{~cm}$ wide. A .7-mA shock was delivered to the grid floor and sides of the shuttlebox by a constant-current shock source consisting of a $600-\mathrm{V}$ ac transformer and a limiting resistor. Shock was scrambled by a Hoffman-Fleshler (1962) relay circuit scrambler.

Procedure. The subjects were randomly assigned to group- and individual-housing conditions, 24 animals to each condition. Until 100 days of age, all animals were handled as in Experiment 1. At 100 days of age, six groups were generated $(n=8$ each). Groups IH and $\mathrm{GH}$ continued to be handled for an additional 10 days. Groups IHE and GHE, in addition to being handled, received ECS ( $40 \mathrm{~mA}$ for $.5 \mathrm{sec}$ through earclips) on three occasions $48 \mathrm{~h}$ apart with a 4-day rest period before shock-escape testing. Groups IHG and GHI consisted of, respectively, individually housed animals and group-housed animals which were subsequently group housed and individually housed, respectively, for a period of 10 days prior to shock-escape testing. Testing consisted of five FR-1 followed by 25 FR-2 shock-escape trials. The .8-mA shock was delivered on a VI 60-sec schedule. Failure to escape resulted in $30 \mathrm{sec}$ of shock. There was no avoidance contingency. Responses and latencies were automatically recorded.

\section{Results and Discussion.}

The mean latency to escape was computed for each rat for both FR-1 and FR-2 trials. A summary of the findings is presented in Table 1. A one-way analysis of variance applied to the FR-1 shock-escape latencies revealed no statistically reliable differences among the groups. A similar analysis of the FR-2 shock-escape latencies revealed a reliable groups effect $[F(5,43)=$ $5.15, \mathrm{p}<.001]$. A subsequent Newman-Keuls analysis $(\mathrm{p}<.05)$ indicated that the $\mathrm{IH}$ animals differed from each of the other groups. No other pair of groups was 
Table 1

Mean Latency in Seconds to Respond on FR-1 (5) and FR-2 (25) Trials in Experiment 3

\begin{tabular}{lrrrr} 
& \multicolumn{4}{c}{ Trial Type } \\
\cline { 2 - 5 } Group & Mean & SE & Mean & SE \\
\cline { 2 - 5 } \cline { 4 - 5 } IH & 5.42 & 1.52 & 24.22 & 2.56 \\
IHE & 2.61 & .37 & 15.53 & 2.72 \\
IHG & s.98 & .48 & 8.47 & .87 \\
GH & 4.68 & 1.31 & 10.97 & 1.64 \\
GHE & 2.75 & .48 & 10.89 & 2.99 \\
GHI & 5.18 & 1.42 & 14.82 & 3.17 \\
\hline
\end{tabular}

Note-Maximum latency is $30 \mathrm{sec} . N=8$ for all groups. $I H=$ individual housing; IHE = individual housing, given ECS; IHG = individual housing followed by group housing; $\mathrm{GH}=$ group housing; $G H E=$ group housing, given ECS; $G H I=$ group housing followed by individual housing.

found to differ. This suggests that the administration of electroconvulsive shock and the period of individual housing after extensive group housing had no disruptive effects. Futhermore, both "therapeutic" procedures, ECS administration and group housing, ameliorated the effects of extensive individual housing. This finding suggests that the disruptive effects of extensive individual housing may be mediated, in part, by a disruption of the noradrenergic system.

\section{GENERAL DISCUSSION}

These experiments point to a parallel between individual housing and exposure to inescapable shock; both result in behavioral deficits in an associative task, and the disruptive effects can be attenuated by procedures which have been reported to result in increases in brain norepinephrine levels.

Rosellini et al. (1976) have proposed that prolonged individual housing results in a maladaptive animal which is prone to "give up" in stressful situations and that the susceptibility to giving up can be potentiated by extensive human handling. While our results are consistent with this statement, the behavioral deficit resulting from prolonged individual housing may be mediated, in part, by some disruption of the noradrenergic system. This finding is particularly important in light of Hughes and Lynch's (1978) concern with the attribution of psychological states to infrahuman animals. It is easier to determine empirically if the behavioral deficit results from norepinephrine disturbance than it is to determine empirically if the animal learns to be "helpless."

The findings also provide evidence for the protective function of group housing, and suggest that personal space allocation and number of animals per group may be factors in the group-housing condition. Lynch and Katcher (1974) were unable to find a difference between their individual- and group-housing conditons. However, in their group-housing condition, animals were housed in pairs and the size of the group cages was not mentioned in their report. That group housing has a protective function is in accord with earlier findings (e.g., Bovard, 1959; Stern, Winokur, Eisenstein, Taylor, \& Sly, 1960; Winokur, Stern, \& Taylor, 1959). The studies reported here also agree with earlier studies which show that individual rearing conditions result in impairment in learning situations (e.g., Bernstein, Borda-Bossana, Atkinson, \& Erlick, 1961; Morgan, 1973) and a reduced ability to tolerate stressful situations (e.g., Winokur et al., 1959).

Although the findings suggest an involvement of the noradrenergic system, it is unclear whether this is brought about by physical stress of individual housing per se or by the psychological stress which accompanies individual housing. Learned helplessness theory offers a paradigm for differentiating the two. In the helplessness paradigm (e.g., Maier et al., 1973), two animals are yoked to each other-one with control over termination of the aversive event, the other with no control. Both receive the same physical stressor. Helplessness theorists (Maier \& Seligman, 1976; Maier, Seligman, \& Solomon, 1969; Seligman, Maier, \& Solomon, 1971) have proposed that it is the psychological factor of lack of control which induces helplessness. Accordingly, if two groups of animals were individually housed from weaning to adulthood and one group had control over some reinforcers such as obtaining food, water, or ambient lighting conditions (after Joffe, Rawson, \& Mullick, 1973) and the other group was treated as in Experiment 1, we can determine if the stress associated with individual housing is due to physical factors or to the psychological stress associated with lack of control. However, if individual housing per se was responsible for the resultant behavioral deficits, then both groups ought to evidence such deficits when tested as adults.

\section{REFERENCE NOTES}

1. Lambert, P. L., Harrell, E. H., \& Emmett-Oglesby, M. W. Electroconvulsive shock improves responding in an animal model of depression. Unpublished manuscript, North Texas State University, 1977.

2. Pavlik, N. P. Personal communication, 1977. On file with M. E. P. Seligman, University of Pennsylvania.

\section{REFERENCES}

Ade R, R. The influence of psychological factors in disease susceptibility in animals, In M. L. Conalty (Ed.), Husbandry of laboratory animals. London: Academic Press, 1967.

Anisman, H. Time-dependent variations in aversively motivated behaviors. Nonassociative effects of cholinergic and catecholinergic activity. Psychological Review, 1975, 82, 359-385.

Bernstein, L., Borda-Bossana, D., Atkinson, H., \& Elrick, $H$. An experimental test of the permanence of learning deficits in the environmentally restricted rat. Journal of Psychosomatic Research, 1961, 5, 127-131. 
Bovard, E. W. The effects of social stimuli in the response to stress. Psychological Review, 1959, 66, 267-277.

Dorworth, T. R., \& Overmier, J. B. On "learned helplessness": The therapeutic effects of electroconvulsive shock. Physiological Psychology, 1977, 3, 355-358.

Glazer, H. I., \& Weiss, J. M. Long term interference effects: An alternative to "learned helplessness." Journal of Experimental Psychology: Animal Behavior Processes, 1976, 2, 202-213.

Hinesley, R. K., Norton, J. A., \& Aprison, M. H. Serotonin, norepinephrine, and 3,4-dihydrophenylethylamine in rat brain parts following electroconvulsive shock. Journal of Psychiatric Research, 1968, 6, 143-152.

Hoffman, H. S., \& Flesher, M. A relay sequencing device for scrambling grid shock. Journal of the Experimental Analysis of Behavior, 1962, 5, 329-330.

Hughes, C. W., \& LYNCH, J. J. A reconsideration of psychological precursors of sudden death in infrahuman animals. American Psychologist, 1978, 33, 419-429.

Joffe, J. M., Rawson, R. A., \& Mulick, J. A. Control of their environment reduces emotionability in rats. Science, 1973, 180, $1383-1384$.

KAUfMAN, I. C. Mother-infant separation in monkeys: An experimental model. In J. P. Scott \& H. C. Senay (Eds.), Separation and depression (Publication No. 94). Washington, D.C: American Association for the Advancement of Science, 1973.

Kety, S. S., Javoy, F., Thierry, A. M., \& Glowinski, J. A sustained effect of electroconvulsive shock on the turnover of norepinephrine in the central nervous system of the rat. Proceedings of the Academy of Natural Sciences, 1967, 58, 1249-1254.

Lessac, M., \& Solomon, R. L. Effects of early isolation in the later adaptive behavior of beagles: A methodological demonstration. Developmental Psychology, 1969, 1, 14-25.

Lynch, J. J., \& Katcher, A. H. Human handling and sudden death in laboratory rats. Journal of Nervous and Mental Disease, 1974, 159, 362-365.

Maier, S. F., Albin, R. W., \& Testa, T. J. Failure to learn to escape in rats previously exposed to inescapable shock depends on the nature of the escape response. Journal of Comparative and Physiological Psychology, 1973, 85, 581-592.

Maier, S. F., \& Seligman, M. E. P. Learned helplessness: Theory and evidence. Journal of Experimental Psychology: General, 1976, 105, 3-46.

Maier, S. F., Seligman, M. E. P., \& Solomon, R. L. Pavlovian fear conditioning and learned helplessness. In B. A. Campell \& R. M. Church (Eds.), Punishment. New York: Appleton-Century-Crofts, 1969.

MorgAN, M. J. Effects of post-weaning environment on learning in the rat. Animal Behaviour, 1973, 21, 429-442.

Richter, C. P. On the phenomenon of sudden death in animals and man. Psychosomatic Medicine, 1957, 19, 191-198.

Rosellini, R. A., Binik, Y. M., \& Seligman, M. E. P.
Sudden death in the laboratory rat. Psychosomatic Medicine, 1976, 38, 55-58.

Scott, J. P., Stewart, J. M., \& DeGhett, V. J. Separation in infant dogs. In J. P. Scott \& H. C. Senay (Eds.), Separation and depression (Publication No. 94). Washington, D. C: American Association for the Advancement of Science, 1973.

Seligman, M. E. P. Helplessness. San Francisco: Freeman, 1975.

Seligman, M. E. P., \& Groves, D. Nontransient learned helplessness. Pscyhonomic Science, 1970, 19, 191-192.

Seligman, M. E. P., Maier, S. F., \& Solomon, R. L. Unpredictable and uncontrollable aversive events. In R. F. Brush (ed.), Aversive conditioning and learning. New York: Academic Press, 1971.

Stern, J. A., Winokur, G., Eisenstein, A., Taylor, R., \& SLY, M. The effects of group vs. individual housing on behavior and physiological response to stress in the albino rat. Journal of Psychosomatic Research, 1960, 4, 185-190.

WEISS, J. M. Effects of coping responses on stress. Journal of Comparative and Physiological Psychology, 1968, 65, 251-260.

WEISs, J. M. Effects of coping behavior in different warning signal conditions on stress pathology in rats. Journal of Comparative and Physiological Psychology, 1971, 77, 1-13. (a)

Weiss, J. M. Effects of coping behavior with and without a feedback signal on stress pathology in rats. Journal of Comparative and Physiological Psychology, 1971, 77, 22-30. (b)

WEISS, J. M. Effects of punishing the coping response (conflict) on stress pathology in rats. Journal of Comparative and Physiological Psychology, 1971, 77, 14-21. (c)

Weiss, J. M., Glazer, H., \& Pohorecky, L. Coping behavior and neurochemical changes in rats: An alternative explanation for the original "learned helplessness" experiments. In G. Serban \& S. Sling (Eds.), Relevance of the psychopathological animal model to the human. New York: Plenum Press, 1976.

Weiss, J. M., Stone, E. A., \& Harrell, N. Coping behavior and brain norepinephrine level in rats. Journal of Comparative and Physiological Psychology, 1970, 72, 153-160.

Welch, A. S., \& Welch, B. L. Isolation, reactivity, and aggression: Evidence for an involvement of brain catecholamines and serotonin. In B. E. Eleftheriou \& J. B. Scott (Eds.), The physiology of aggression and defeat. New York: Plenum, 1971.

Winokur, G., Stern, J., \& TAYlor, R. Early handling and group housing: Effect on development and response to stress in the rat. Journal of Psychosomatic Research, 1959, 4, 1-4.

\section{NOTE}

1. We share with Hughes and Lynch (1978) the ethical concerns about the operations used in Experiment 1. Our animals were treated in accordance with the APA Principles and Care for the Use of Animals (1971).

(Received for publication June 18, 1979; revision accepted November 19, 1979.) 